This item was submitted to Loughborough's Research Repository by the author.

Items in Figshare are protected by copyright, with all rights reserved, unless otherwise indicated.

\title{
Developing a methodology for catalytic asymmetric crotylation of aldehydes
}

PLEASE CITE THE PUBLISHED VERSION

https://doi.org/10.1055/s-0040-1706659

PUBLISHER

Thieme Publishing

VERSION

AM (Accepted Manuscript)

PUBLISHER STATEMENT

This paper was accepted for publication in the journal Synlett and the definitive published version is available at https://doi.org/10.1055/s-0040-1706659.

\section{LICENCE}

CC BY-NC-ND 4.0

\section{REPOSITORY RECORD}

Rubtsov, Aleksandr E, and Andrei Malkov. 2021. "Developing a Methodology for Catalytic Asymmetric Crotylation of Aldehydes”. Loughborough University. https://hdl.handle.net/2134/13614551.v1. 


\section{Developing Methodology for Catalytic Asymmetric Crotylation of Aldehydes}

\author{
Aleksandr E. Rubtsova \\ Andrei V. Malkov*b \\ a Department of Chemistry, Perm State University, Bukireva \\ 15, Perm 614990, Russia. E-mail: rubtsov@psu.ru \\ ${ }^{b}$ Department of Chemistry, Loughborough University, \\ Loughborough, LE11 3TU, UK. E-mail: A.Malkov@lboro.ac.uk \\ * indicates the main/corresponding author. \\ Click here to insert a dedication
}

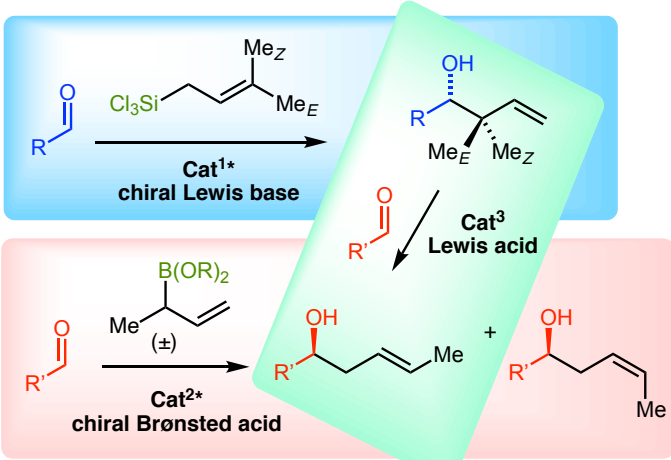

with aldehydes $\mathbf{2}$ through cyclic chair-like transition state $\mathbf{3}$ (Scheme 1). This results in an excellent diastereocontrol in the case of $\gamma$-substituted allylmetals $\mathbf{1}$.

Abstract Asymmetric crotylation has firmly earned a place among valuable synthetic tools for stereoselective construction of carbon skeleton. For a long time, the field was heavily dominated by the reagents bearing stoichiometric chiral auxiliaries, but presently, catalytic methods are gradually taking central stage, and the area continues to develop rapidly. This account primarily focuses on preformed organometallic reagents based on Silicon and to some extent Boron. It narrates our endeavour in designing new efficient chiral Lewis base catalysts for the asymmetric addition of crotyltrichlorosilanes to aldehydes. Next, it covers the development of a novel protocol for kinetic resolution of racemic secondary allylboronates that give rise to enantio- and distereomerically enriched linear homoallylic alcohols. As a separate topic, cross-crotylation of aldehydes using enantiopure branches homoallylic alcohols as a source of crotyl group is discussed. Finally, the synthetic credentials of the developed methodology are illustrated by the total synthesis of marine natural products where crotylation plays a key role in setting up stereogenic centers.

1. Introduction

2. Pyridine $\mathrm{N}$-Oxides as Lewis Base Catalysts

3. Bipyridine $\mathrm{N}, \mathrm{N}^{\prime}$-Dioxides as Lewis Base Catalyst

4. Chiral Allylating Reagents

5. Synthetic Applications

6. Concluding Remarks

Key words allylation, asymmetric catalysis, crotylation, enantioselectivity, stereoselectivity, Lewis bases

\section{Introduction.}

Asymmetric nucleophilic allylation of carbonyl compounds is a powerful synthetic methodology for stereoselective construction of C-C bond. It had already earned a place among the established synthetic tools when we entered the field nearly two decades ago.1-3 This area continues to expand, particularly with introduction of novel approaches and methods for asymmetric crotylation of carbonyl compounds. ${ }^{4-8}$ This account will primarily focus on preformed organometallic reagents, where the most practical from the synthetic viewpoint are the reagents of Type 1 , according to classification by Denmark and Weber, ${ }^{9}$ that react

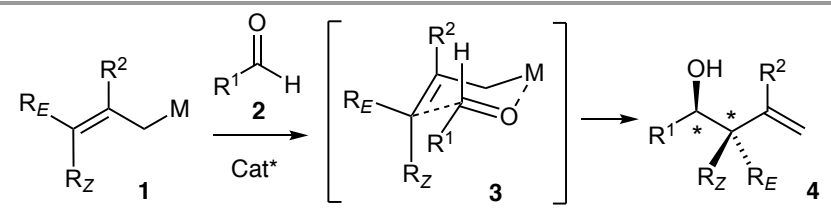

Scheme 1 Asymmetric allylation of aldehydes

Here, E-configured derivatives afford anti-diastereoisomers 4, whereas the respective $Z$-isomers give rise to $s y n$-alcohols. Type 1 allylmetals are typically represented by $\mathrm{B}$ - and $\mathrm{SiCl}_{3}$-based reagents. What became apparent, however, that despite advances in the development of catalytic asymmetric allylation of carbonyl compounds, ${ }^{3}$ the related crotylation methodology remained a challenging problem and was dominated by stoichiometric chiral reagents, such as allylboron derivatives $\mathbf{5}$ and $\mathbf{6}$ introduced respectively by Brown ${ }^{10,11}$ and Raush. ${ }^{12,13}$ For silicon, similar type reagents 7 were reported by Leighton ${ }^{14,15}$ (Scheme 2).

Despite their dominance, synthesis of crotylboron reagents 5 and 6 is associated with practical challenges, as it involves low temperature careful deprotonation of cis- or trans-2-butene followed by the reaction with an appropriate boron source. Furthermore, crotylboranes $\mathbf{5}$ are prone to borotropic rearrangement even at sub-zero temperatures resulting in scrambling of $E / Z$ geometry, which adds additional constraints to their application. At the same time, boronates $\mathbf{6}$ and particularly silicon reagents $\mathbf{7}$ are configurationally stable and hence more practical. It is important to note that allyltrichlorosilanes $\mathbf{8}$, serving as precursors to 7, are useful reagents in their own right. Simple crotyl derivatives can be readily synthesized in geometrically pure form either by Pd-catalyzed 1,4hydrosilylation of butadiene $(Z-8)$ or by $\mathrm{Cu}$-catalyzed coupling of 
$E$-crotyl chloride with trichlorosilane $(E-8) \cdot{ }^{16}$ They can be activated by catalytic quantities of chiral Lewis bases for enantioselective addition to aldehydes. ${ }^{17}$

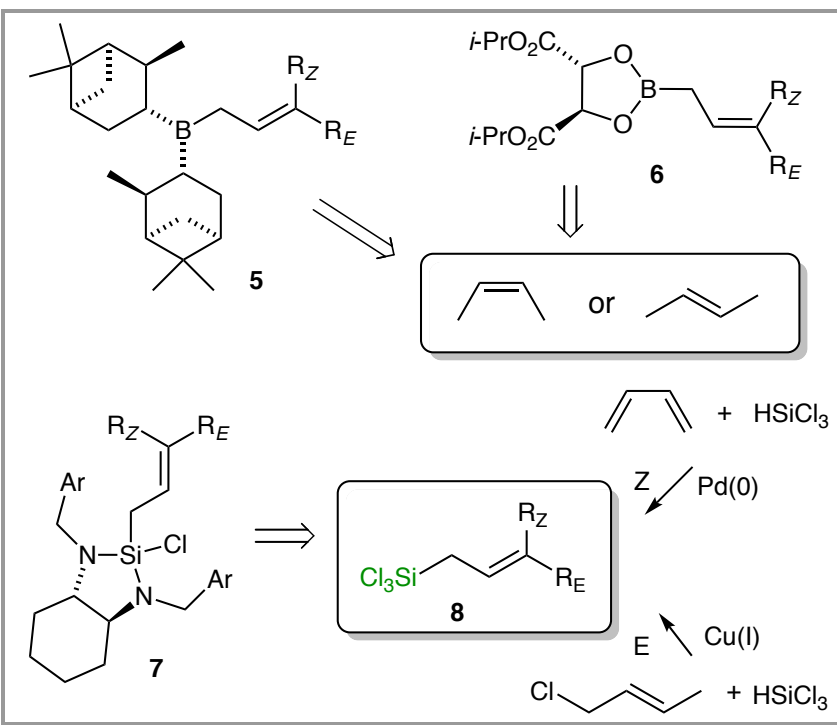

Scheme 2 Chiral auxiliary based reagents for asymmetric crotylation of aldehydes.

In practice, crotylsilanes $Z-\mathbf{8}$ and $E-\mathbf{8}$ generally are less moisture sensitive than the trichlorosilane itself. Due to the simplicity of the protocols, asymmetric allylation of aldehydes $\mathbf{2}$ with allyltrichlorosilanes 1, catalyzed by Lewis bases (Scheme 1), has become a benchmark for new chiral nucleophilic catalysts. The most successful catalysts feature a strongly Lewis basic oxygen capable of coordinating to silicon as a key structural element. The compound classes include chiral phosphoramides, chiral phosphine oxides, chiral $N$-oxides, chiral sulfoxides and amides/formamides, which were subject to comprehensive reviews.18-22 Our contribution to this area involves the development of chiral pyridine $\mathrm{N}$-oxides as efficient catalysts for enantio- and diastereoselective crotylation of aldehydes.

\section{Pyridine $\mathbf{N}$-Oxides as Lewis Base Catalysts}

The research discussed in this section was carried out in alliance with Pavel Kocovsky at the University of Glasgow and evolved from the work on chiral bipyridines as ligands for transition metal catalysis. ${ }^{23,24}$

Following the report by Nakajima 25 that axially chiral biquinoline $N, N$ '-dioxide 9 (Figure 1) can serve as an efficient catalyst for the allylation of aromatic aldehydes with high yield and enantioselectivity (ee up to $92 \%$ at $78{ }^{\circ} \mathrm{C}$ ), we first tested dioxide $\mathbf{1 0}$ obtained by oxidation of the respective bipyridine with $m$ CPBA. However, in the model allylation of benzaldehyde with a simple allyltrichlorosilane the homoallylic alcohol was obtained in only $41 \%$ ee. In contrast, 11a turned out to be more efficient, showing $92 \%$ ee in the same reaction. ${ }^{26,27}$

Assuming that coordination of $\mathrm{N}$-oxide 11a to silicon results in a twist about the bond linking the two pyridine units, this would create a chiral axis. The role of this additional element of chirality was examined with the aid of two atropisomeric catalysts 11b. In the model allylation of benzaldehyde, catalysts $(+)-\mathbf{1 1 b}$ produced the same enantiomer of the product as was observed with 11a, but with improved enantioselectivity (98\%), whereas atropisomer (-)-11b gave the opposite enantiomer of the product in a lower ee (82\%), revealing the crucial role of the chiral axis in controlling the sense of enantiomeric induction in this system. ${ }^{27}$
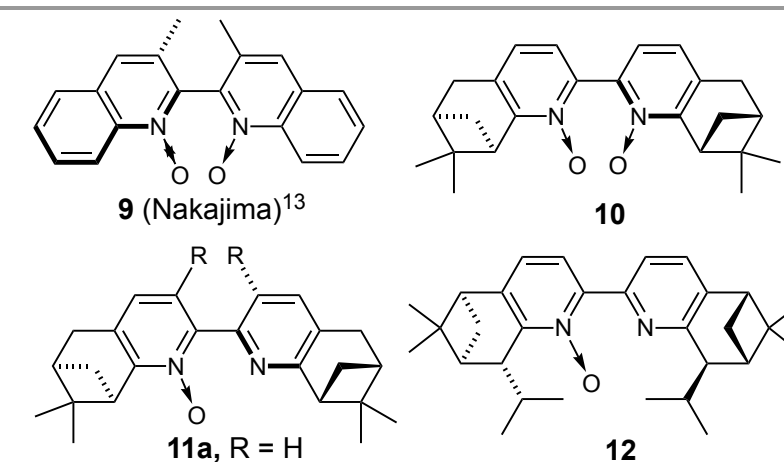

10

11a, $\mathrm{R}=\mathrm{H}$

11b, $\mathrm{R}=\mathrm{Me}$

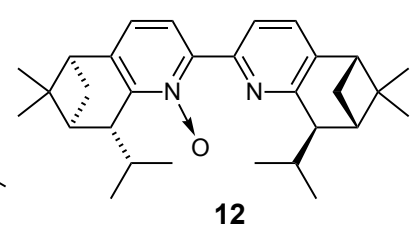

12
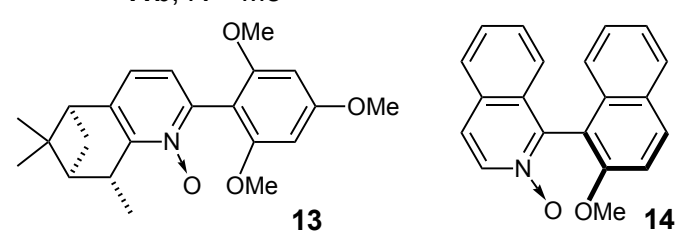

Figure 1 Mono $\mathrm{N}$-oxide catalysts

However, mono $N$-oxides $\mathbf{1 1 b}$ proved to be configurationally unstable slowly interconverting at room temperature in solution. Therefore, an alternative mono $N$-oxide analogue 12 was developed showing enantioselectivity comparable to (+)-11b. ${ }^{26}$ Further, we demonstrated that the second pyridine unit in the catalysts structure is not required. Terpene-derived $\mathrm{N}$-oxide $\mathbf{1 3}$ $\left(\right.$ METHOX) 28-31 and axially chiral analogue 14 (QUINOX) ${ }^{32,33}$ proved to be among the most efficient catalysts for the asymmetric allylation of aldehydes with allyltrichlorosilane.

Table 1 Asymmetric crotylation catalyzed by mono $\mathrm{N}$-oxides.

\begin{tabular}{|c|c|c|c|c|c|c|}
\hline & $\underbrace{\mathrm{SiC}}_{(Z)-8 \mathrm{~B}}$ & $\underset{\text { Catalyst }}{\stackrel{\mathrm{Ph}}{\stackrel{\mathrm{O}}{\longrightarrow}}}$ & $\begin{array}{c}\prod_{\mathrm{Me}} \\
\text { anti-15a }\end{array}$ & & syn-16 & \\
\hline Entry & $\begin{array}{l}\text { Catalyst } \\
(\mathrm{mol} \%)\end{array}$ & 8 & $\begin{array}{l}\text { Solvent, } \\
\mathrm{T} \text { 으 }\end{array}$ & $\begin{array}{l}\text { Yield, } \\
\%\end{array}$ & $15 / 16$ & $\begin{array}{l}\text { Ee, } \\
\%\end{array}$ \\
\hline 1 & 11a (10) & $\begin{array}{l}\mathbf{8 b} \\
(E / Z 87: 13)\end{array}$ & $\begin{array}{l}\mathrm{CH}_{2} \mathrm{Cl}_{2}, \\
-60\end{array}$ & 54 & $93: 7$ & 87 \\
\hline 2 & $12(10)$ & $\begin{array}{l}8 b \\
(E / Z 87: 13)\end{array}$ & $\begin{array}{l}\mathrm{MeCN}, \\
-40\end{array}$ & 88 & $98: 2$ & 98 \\
\hline 3 & $12(10)$ & $\begin{array}{l}8 c \\
(E / Z 2: 98)\end{array}$ & $\begin{array}{l}\mathrm{MeCN}, \\
-40 \\
\end{array}$ & 37 & $10: 90$ & 87 \\
\hline 4 & $13(5)$ & $\begin{array}{l}8 \mathbf{b} \\
(E / Z 87: 13)\end{array}$ & $\begin{array}{l}\mathrm{MeCN}, \\
-40 \\
\end{array}$ & 90 & $99: 1$ & 97 \\
\hline 5 & $13(5)$ & $\begin{array}{l}8 c \\
(E / Z 2: 98)\end{array}$ & $\begin{array}{l}\mathrm{MeCN}, \\
-40\end{array}$ & 26 & $14: 86$ & 26 \\
\hline 6 & $14(5)$ & $\begin{array}{l}8 b \\
(E / Z 87: 13)\end{array}$ & $\begin{array}{l}\mathrm{CH}_{2} \mathrm{Cl}_{2}, \\
-40 \\
\end{array}$ & 70 & $68: 32$ & 65 \\
\hline 7 & $14(5)$ & $\begin{array}{l}8 b \\
(E / Z 98: 2)\end{array}$ & $\begin{array}{l}\mathrm{CH}_{2} \mathrm{Cl}_{2}, \\
-40 \\
\end{array}$ & 65 & $95: 5$ & 66 \\
\hline 8 & $14(5)$ & $\begin{array}{l}8 c \\
(E / Z 2: 98)\end{array}$ & $\begin{array}{l}\mathrm{CH}_{2} \mathrm{Cl}_{2}, \\
-40\end{array}$ & 78 & 1:99 & 79 \\
\hline
\end{tabular}

aThe reactions were carried out on a $0.4-1 \mathrm{mmol}$ scale; ee of the main isomer is shown. 
In the asymmetric crotylation of aldehydes employing $\mathrm{N}$-oxides 11-14, two different patterns of reactivity were observed (Table 1). ${ }^{30,33}$ Thus, terpene-derived Lewis bases 11a, 12 and $\mathbf{1 3}$ showed kinetic preference towards trans isomer $\mathbf{8 b}$ (Table 1, entries 1-5), whereas QUINOX 14 promoted faster reaction rates with cis isomer 8c (entries 6-8). For example, with the former group of catalysts, crotylsilane $(E)$-8b, which was an 87:13 mixture of geometrical isomers, furnished anti-15a in 93:7 to 99:1 d.r. with high enantiomeric purity. At the same time, the reaction of crotylsilane $(Z)-\mathbf{8 c}$ in the presence of $\mathbf{1 2}$ and $\mathbf{1 3}$ proved to be much slower and showed lower enantioselectivity (entries 3 and 5). Note the particular difference in the reactivity exhibited by METHOX 13 (entries 4 and 5). The kinetic preference of QUINOX $\mathbf{1 4}$ towards cis isomer $\mathbf{8 c}$ is reflected in the enrichment of the product with syn isomer 16a (entry 6), though the effect is less prominent than in the case of METHOX 13 Furthermore, the two mono $N$-oxides $\mathbf{1 3}$ and $\mathbf{1 4}$ also differ in the reactivity towards substituted aromatic aldehydes. While METHOX 13 retained the same pattern of reactivity shown for benzaldehyde and gave pure anti-configured products $\mathbf{1 5}$ of high enantiopurity even with a $87: 13 \mathbf{8 b} / \mathbf{8 c}$ mixture, crotylation catalyzed by QUINOX 14 proceeded slightly faster with Z-8c and showed high enantio- and diastereoselectivity only with electron poor aldehydes, whereas with electron-rich aldehydes a drop in both d.r. and ee was observed.

The dramatic difference in the catalytic behavior of $\mathbf{1 3}$ and $\mathbf{1 4}$ was investigated with the aid of kinetic and computational studies.30,33 While kinetically both catalysts showed a similar pattern, DFT computations suggested different transition state arrangements (Scheme 3). METHOX appears to prefer an ionic transition state (TS A) with a pentacoordinate silicon, whereas QUINOX favours the neutral, hexacoordinate species (TS B). This can also explain the experimentally observed optimal solvents for the two catalysts, namely the polar acetonitrile for METHOX and nonpolar dichloromethane for QUINOX. The difference in the TS structures can result from the increased steric size of METHOX 13, which disfavors the sterically more demanding hexacoordinate complex. Such a mechanistic dichotomy seems to be the most likely cause behind the contrasting stereochemical outcomes in the crotylation reactions employing $\mathbf{1 3}$ and $\mathbf{1 4}$ as catalysts.

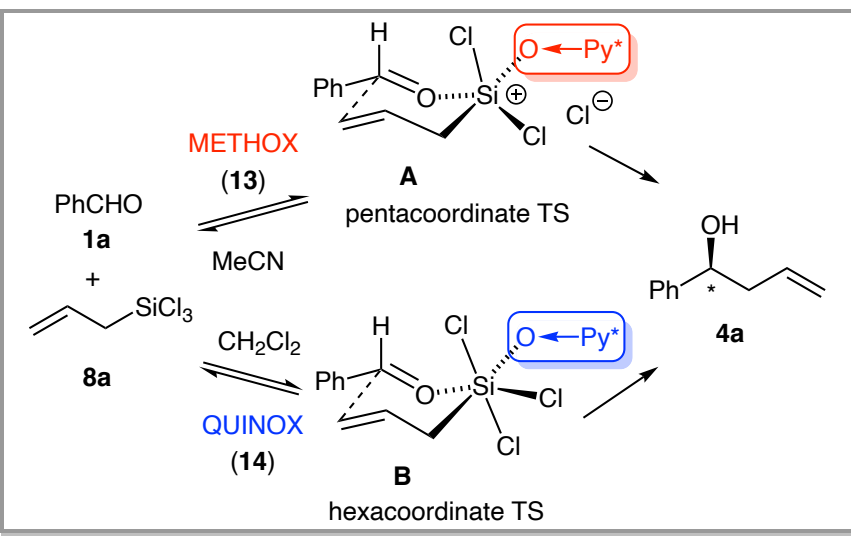

Scheme 3 Mechanistic dichotomy in the allylation reaction catalysed by chiral pyridine-N-oxides. $P y^{*} \rightarrow O$ designate chiral pyridine $N$-oxides 13 or 14 .

Pyridine mono- $N$-oxides 11-14 proved to be good, practical catalysts for asymmetric crotylation of aromatic and unsaturated aldehydes. In particular, METHOX 13 showed high stereocontrol across a wide range of substituted aldehydes, except for aliphatic derivatives, it also exhibited a unique kinetic preference towards E-crotyltrichlorosilane. QUINOX 14 was highly efficient in the crotylation of electron-poor aromatic aldehydes with a slight preference for $Z$-crotyltrichlorosilane but was poor with electron rich aromatic aldehydes. Such a specific selectivity, however, exposed a significant gap in the methodology, namely inability to accomplish crotylation of electron-reach aldehydes with $Z$ crotyltrichlorosilane to furnish enantioenriched syn-alcohols $\mathbf{1 6}$. Therefore, we next embarked on developing more universal catalysts that would retain high efficacy across a wide array of reagents and substrates.

\section{Bipyridine $N, N^{\prime}$-Dioxides as Lewis Base Catalysts}

It is well documented that chiral bipyridine- $N, N^{\prime}$-dioxides are highly efficient catalysts for asymmetric allylation of aldehydes with allyltrichlorosilanes. ${ }^{19,20,34}$ In addition to Nakajima's dioxide $\mathbf{9}$, a selection of other successful bipyridine $N, N$-oxides $\mathbf{1 7}, 35,36$ 18, ${ }^{37} 19^{38,39}$ and $\mathbf{2 0}^{40}$ is shown in Figure 2.

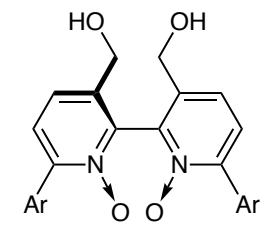

17<smiles></smiles>

19<smiles>[O-][n+]1c(-c2ccccc2)cc2c(c1-c1c3c(cc(C4CCCO4)[n+]1[O-])CCCC3)CCCC2</smiles>

$18\left(S_{\mathrm{ax}}, R\right)$

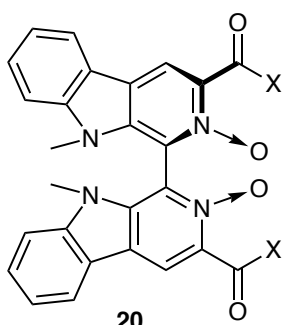

Figure 2 Bipyridine $N, N^{\prime}$-doixide catalysts

Generally, in the asymmetric crotylation catalyzed by bis- $N, N^{\prime}-$ dioxides, the syn/anti ratio $(\mathbf{1 5 / 1 6})$ closely reproduces the geometrical purity of the reagents $\mathbf{8 b}$ and $\mathbf{8 c}$, which contrasts with the reactions mediated by mono- $N$-oxide discussed in the previous section. However, syntheses of $\mathbf{9 , 1 7 - 2 0}$ is not trivial and either involve lengthy sequences or give low overall yield, which makes them unsuitable for larger scale applications. For example, to obtain enantioenriched catalyst $19(\mathrm{Ar}=\mathrm{Ph})$ we had to resolve the racemate by preparative chiral HPLC, ${ }^{39}$ hence only small quantities were available for test reactions.

Therefore, a set of novel axially chiral bis- $N$-oxides $\mathbf{2 6}$ has been designed that can be synthesized in 4 easy steps from inexpensive starting materials (Scheme 4). Synthesis of chiral monomeric $\mathrm{N}$-oxides 25a-j was accomplished in three steps from commercially available ketones $\mathbf{2 1}$ by Kröhnke annulation of $\mathbf{2 2}$ and $(1 R)$-myrtenal 23 to afford pyridines $\mathbf{2 4}$ that were further oxidized with $m$ CPBA to $\mathbf{2 5}$ (Scheme 2).41,42 Oxidative dimerization of $\mathbf{2 5}$ into $\mathbf{2 6}$ uses $\mathrm{O}_{2}$ as a terminal oxidant and relies on the capture of kinetically formed organolithium complexes. The oxidation can also be carried out in an 
electrochemical cell. Importantly, dioxide $\mathbf{2 6}$ were formed as single diastereoisomers (d.r. > 25:1) in good yield in under 15 $\min$.

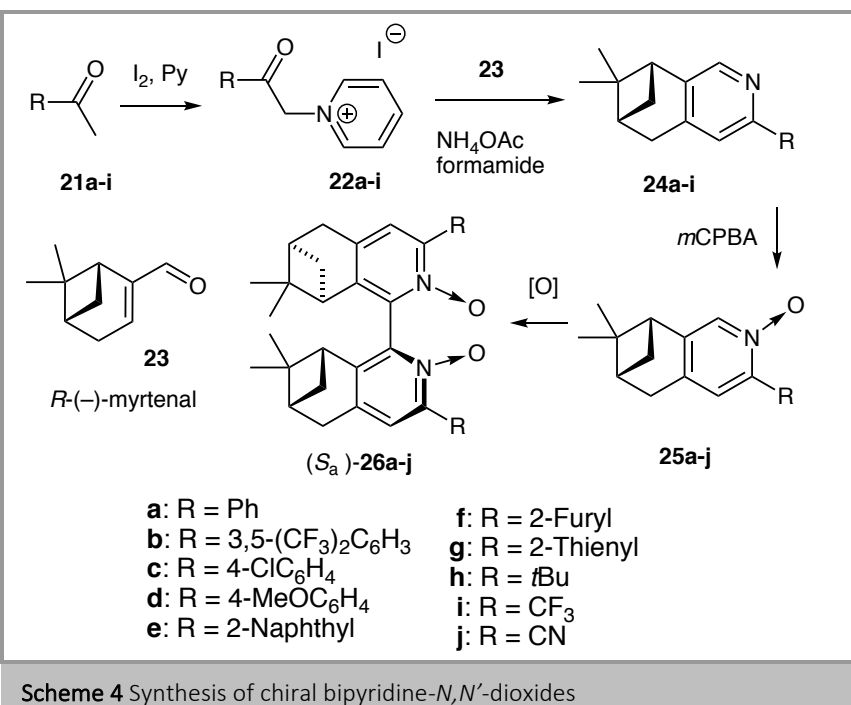

Bipyridine- $N, N^{\prime}$-dioxide 26b proved to be a highly competent catalysts for the crotylation of aromatic and unsaturated aldehydes (Table 2), where the diastereomeric ratio of $\mathbf{1 5 / 1 6}$ reflected the geometrical purity of the starting reagents $\mathbf{8 b} / \mathbf{8 c}$.

Table 2 Asymmetric crotylation catalyzed by bipyridine $N, N^{\prime}$-dioxides. ${ }^{a}$

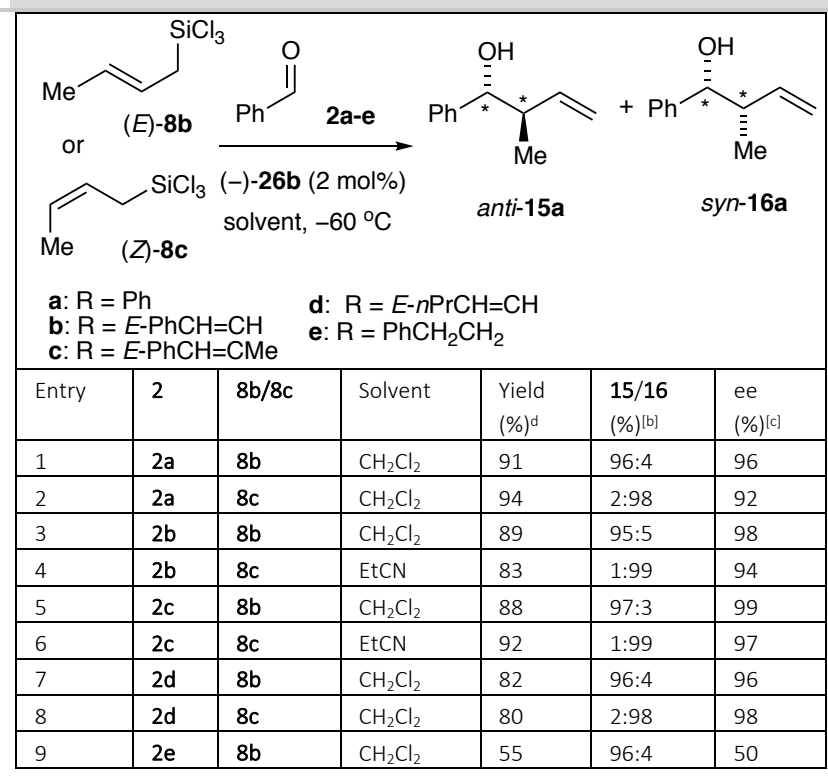

a] Unless stated otherwise, the reactions were carried out on a $0.5 \mathrm{mmol}$ scale at $60{ }^{\circ} \mathrm{C}$ for $24 \mathrm{~h}$ with $2 \mathrm{~mol} \%$ loading of (-)-26b, 1.7 eq of $E-8 \mathrm{~b}(E / Z$ 95:5) or Z-8c (Z/E $98: 2$ ) and 2.0 eq of $i \mathrm{Pr}_{2} \mathrm{EtN}$; [b] determined by $1 \mathrm{H}$ NMR or GC from the crude mixture; $[c]$ ee of the major isomer, the absolute configuration is $(1 R, 2 R)$ for 15 and $(1 R, 2 S)$ for 16 .

Dichloromethane was identified as the optimal solvent, propionitrile showed comparable results and in some instances propionitrile produced slightly better diastereoselectivities with $Z$-8c (entries 4 and 6). In contrast to the high enantioselectivity obtained with unsaturated aldehydes, aliphatic $2 \mathbf{e}$ exhibited lower reactivity with $\mathbf{8 b}$ and gave the product $\mathbf{1 4 b}$ in low ee (entry 9), which represented a common trend for the reactions with allyltrichlorosilanes. However, a highly enantioselective allylation of aliphatic aldehydes with allyltrichlorosilanes can be accomplished using a quinine-derived catalyst. ${ }^{43}$

\section{Chiral Allylating Reagents}

This section will cover reagents containing stereogenic center(s), which include branched homoallylic alcohols and chiral allylboronates.

Due to the reaction with reagents of Type 1 proceed by a cyclic transitions state $\mathbf{3}$ (Scheme 1), only branched alcohols $\mathbf{4}$ are produced, whereas linear isomers usually are not observed. At the same time, Nokami and co-workers showed that branched diastereoisomers $\mathbf{1 5}$ and $\mathbf{1 6}$ in the presence of aldehyde and a Lewis acid can rearrange into the respective linear products. ${ }^{44,45}$ To take this further, we developed a practical method for the catalytic asymmetric cross-crotylation (Scheme 5). ${ }^{46}$ In this protocol, the enantiopure anti-homoallylic alcohol 27, which for the best results should be obtained from tolualdehyde, is treated with an aliphatic aldehyde $\mathbf{2}$ in the presence of a Lewis acid, such as (TfO) ${ }_{2} \mathrm{Sn}$, to afford the homoallylic alcohol 31. This cascade involves the Lewis (or Brønsted) acid mediated formation of the oxonium ion $\mathbf{2 8}$ that undergoes a sigmatropic rearrangement to generate another oxonium ion 30, which upon hydrolysis furnishes the new homoallylic alcohol $(E)-31$. Due to the cyclic transition state 29, where all substituents are equatorial if the starting alcohols $\mathbf{2 7}$ is anti-configured, the allyl transfer proceeds with a complete retention of chirality, and the reaction furnishes geometrically pure linear alcohols $E-\mathbf{3 1}$. The scope of the crosscrotylation includes aliphatic and electron-deficient aromatic aldehydes 2 .

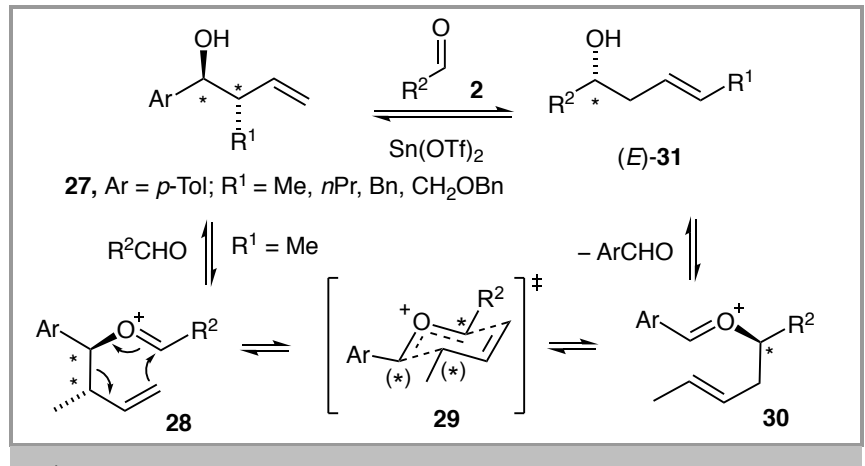

Scheme 5 Catalytic cross-crotylation reaction

This allyl-transfer method was extended to bifunctional disilane 32,47 which featured two allylsilane fragments with an orthogonal reactivity (Scheme 6). Homoallylic alcohols $\mathbf{3 3}$ were obtained in a highly stereocontrolled fashion by a Lewis base catalyzed allylation of aromatic aldehydes employing dioxide $\mathbf{1 8}$ ( $\leq 98 \%$ ee and $\geq 99: 1 \mathrm{dr}$ ). Reaction of the product 33 with another aldehyde, now catalyzed by ( $\mathrm{TfO})_{2} \mathrm{Sn}$, triggered a cascade including the formation of the oxonium ion 34, whose [3,3]sigmatropic rearrangement generated another oxonium ion $\mathbf{3 5}$ with a new allylsilane moiety set for the final intramolecular allylation. The resulting all-cis trisubstituted tetrahydrofurans 36 at $-90^{\circ} \mathrm{C}$ were obtained in high diastereoselectivity $(\leq 25: 1)$ with retention of chirality. 


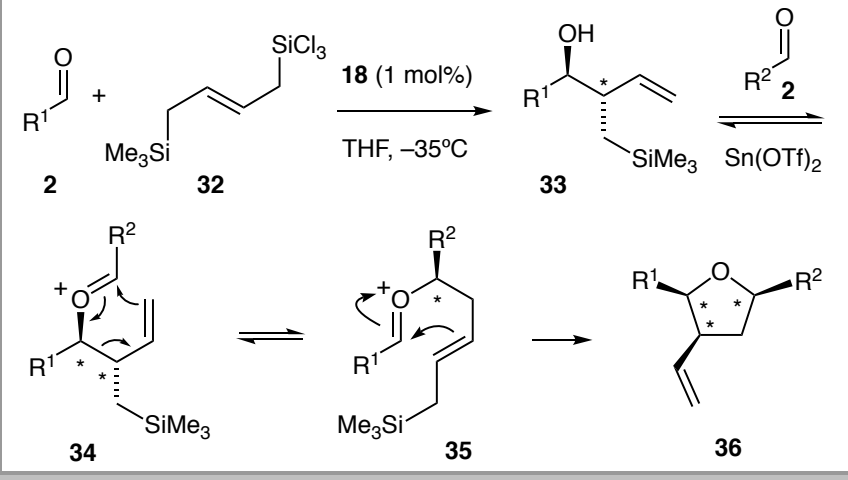

Scheme 6 Cascade allylations using bifunctional disilane 32 .

The catalytic cross-crotylation method offers highly stereoselective access to $E$ linear alcohols $\mathbf{3 1}$. The allyl transfer reaction can be also used for the synthesis of linear $Z$-homoallylic alcohols 38,48,49 but the method employs 2 - to 3 -fold excess of a stoichiometric chiral auxiliary reagent.

An alternative approach to linear homoallylic alcohols involves the use of secondary allylmetal reagents 37 (Scheme 7). However, due to the competing transition states $\mathbf{C}$ and $\mathbf{D}$, depending on the size of the metal fragment, a mixture of $E$ and $Z$ linear alcohols $\mathbf{3 1}$ and $\mathbf{3 8}$ is usually obtained. In addition, the geometrical isomers belong to the opposite enantiomeric series. $^{50,51}$ In the case of secondary allylboronates, larger pinacolate group favors the formation of $Z$ isomer, whereas smaller dimethoxy group gives rise to $E$ isomer preferentially. ${ }^{52}$

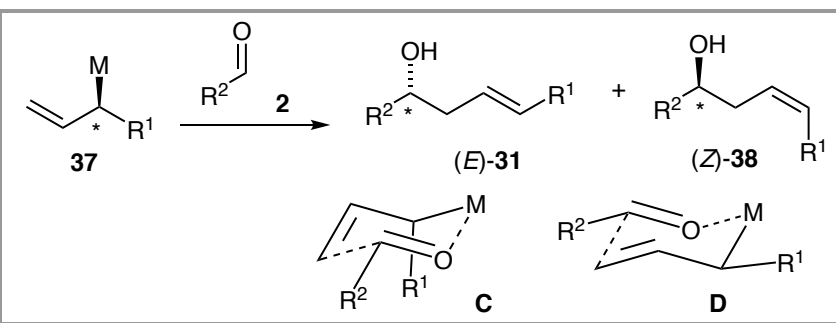

Scheme 7 Crotylation employing chiral allylmetal reagents 37

Taking into account that chiral Brønsted acid catalysts can competently control enantiofacial selectivity, 53,54 it was reasonable to assume that such catalysts with racemic secondary allylboronates $\mathbf{3 7}$ should also favor formation of $\mathbf{3 1}$ and $\mathbf{3 8}$ of the same enantiomeric series. Indeed, resolution of racemic pinacolboronate $37\left(\mathrm{M}=\right.$ Bpin, $\left.\mathrm{R}^{1}=\mathrm{Me}\right)$ gave a 4:1 mixture of $(Z)$ 38 and $(E)$-31 with high enantioselectivity (98\% and 96\%, respectively) and, importantly, with the same absolute configuration at the stereogenic center. To boost diastereoselectivity, DFT calculations identified tetraethylethyleneglycol boronate scaffold (B(Epin)) 39 as optimal to favor the $Z$-selectivity (Scheme 8). ${ }^{55}$ The reaction scope included a wide range of aromatic and aliphatic aldehydes to afford Z-homoallylic alcohols in high geometrical and enantiomeric purity. Furthermore, the introduced by us Epin fragment played an additional role of improving the hydrolytic stability of the boronates, thus allowing easy chromatographic purification of the allylboronates remaining unreacted after the kinetic resolution process.

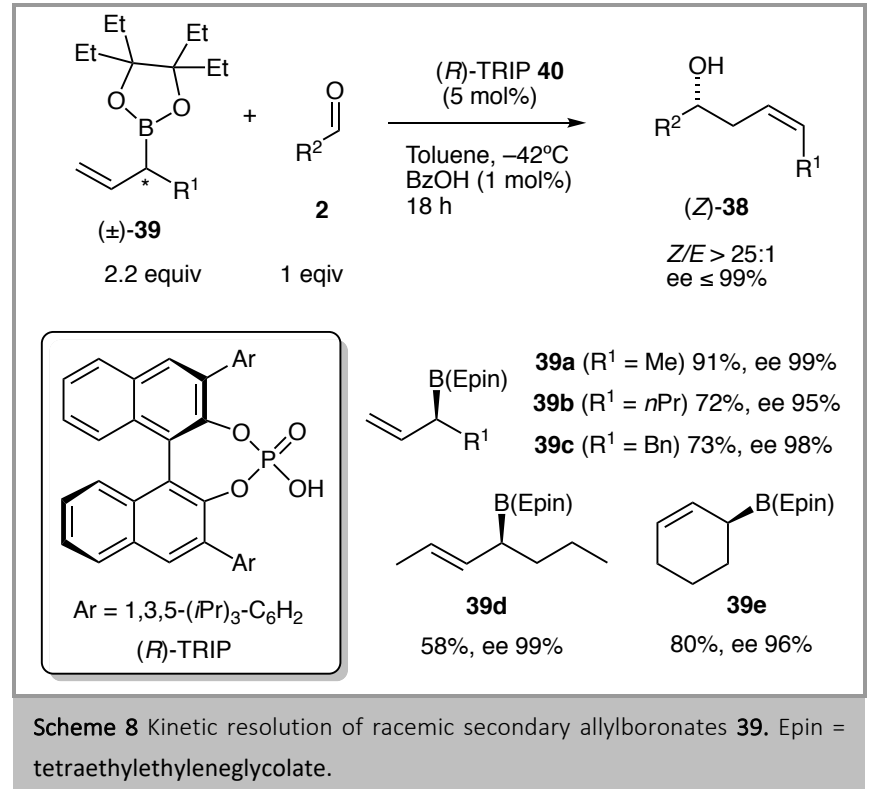

The process was tuned to obtain chiral boronates 39a-e in high enantiomeric purity, which were then applied in the synthesis of chiral homoallylic amines (Scheme 9). ${ }^{56}$ To avoid uncertainties in the stereochemical outcome of the reaction brought about by substituents on the imine nitrogen, we opted for unsubstituted imines with the steric size similar to aldehydes. The $\mathrm{NH}$ aldimines, due to their poor stability, were synthesized in situ from aldehydes in a $4 \mathrm{M}$ solution of ammonia in ethanol at $0{ }^{\circ} \mathrm{C}$ following literature protocol. ${ }^{57}$

Scheme 9 Synthesis of chiral homoallylic amines

A wide range of chiral homoallylic amines $\mathbf{4 2}$ with Z-configured internal double bond was obtained by reacting the enantioenriched boronates 39a-e with imines formed in situ. The method is characterized by an excellent chirality transfer and high stereoselectivity benefiting from the increased steric radius of the Epin fragment.

\section{Synthetic Applications}

The power of the methodology for asymmetric crotylation of carbonyl compounds is best illustrated by application in targetoriented stereoselective synthesis. In our program on developing new antibacterial agents, we became interested in secondary 
metabolites isolated from marine soft coral Pseudopterogorgia elisabethae that exhibited a wide range of useful biological properties including anti-tubercular, anti-inflammatory, antimicrobial and cytotoxic activities. ${ }^{58-60}$ Specifically, we focused on two diterpenoids $\mathbf{4 3}$ and $\mathbf{4 4}$ possessing serrulatane skeleton (Figure 3).61-65,66<smiles>CC(C)=CCCC(C)c1cc(C)ccc1C(C)C</smiles>

(+)-Erogorgiaene

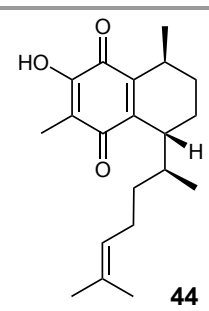

(+)-Elisabethadieone
Figure 3 Serrulatane diterpenes from Pseudopterogorgia elisabethae

General retrosynthetic analysis of $\mathbf{4 3}$ (erogorgiaene) and $\mathbf{4 5}$ (precursor to elisabethadione 44 ) is shown in Scheme 10. It identifies suitably substituted $\alpha$-methylcinnamaldehyde $\mathbf{4 9}$ as a key achiral intermediate. Asymmetric crotylation of the latter with 1 affords alcohol $\mathbf{4 8}$ followed by anionic oxy-Cope rearrangement yielding $\mathbf{4 7}$. This reaction sequence creates two out of three stereogenic centers of the serrulatane skeleton. Extension of the side chain through Wittig alkenylation followed by cationic cyclization installs the final stereogenic center (46). This general strategy for constructing the serrulatane framework relies on enantioselective crotylation of aldehyde $\mathbf{4 9}$ to give synalcohol 48 followed by stereoselective anionic oxy-Cope rearrangement (AOC) (Scheme 10). Importantly, both the $\alpha$ methyl of the cinnamyl fragment and the syn configuration of the homoallylic alcohol $\mathbf{4 8}$ play a critical role in the efficient transfer of chirality during the AOC rearrangement, as shown by comparison of two possible chair-like transition structures $\mathbf{E}$ and F, where the TS F is disfavored due to the 1,3-pseudodiaxial clash (Scheme 10).

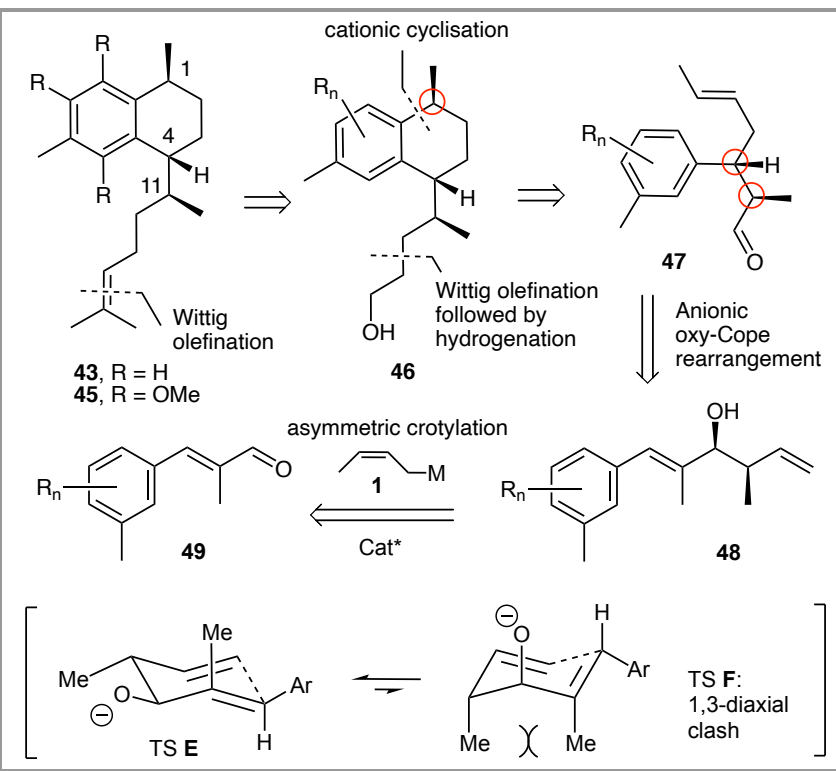

Scheme 10 Retrosynthetic analysis of serrulatane diterpenes
The requisite syn-alcohols $\mathbf{5 1}$ and $\mathbf{5 3}$ were obtained by crotylation of the respective cinnamaldehydes $\mathbf{5 0}$ and $\mathbf{5 2}$ employing terpene-derived $N, N^{\prime}$-dioxide $\mathbf{2 6} \mathbf{b}$ as a catalyst (Scheme 11). In the total synthesis of (-)-elisabethadione 44, the enantiomer of the naturally occurring compound, asymmetric crotylation of cinnamaldehyde $\mathbf{5 0}$ on a $5 \mathrm{mmol}$ scale afforded synhomoallylic alcohol (-)-51 in 82\% yield, 94\% ee and with complete distereoselectivity. ${ }^{41}$ Anionic oxy-Cope rearrangement followed by protonation of the resulting enolate afforded the respective aldehyde $\mathbf{4 7}$ with d.r. 3:1. Cationic cyclization to form the C1 stereocenter proved to be highly selective (d.r. 25:1). Alcohol 46 was purified by preparative HPLC, paving the way for completion of the synthesis of distereomerically pure (-)-44. ${ }^{41}$.

Synthesis of (-)-erogorgiaene $\mathbf{4 3}$, the enantiomer isolated from brown alga, was accomplished using the same reaction sequence. However, to avoid the issue of regioselectivity in the cationic cyclization of 47, 2-bromo substituted cinnamaldehyde $\mathbf{5 2}$ was chosen as the substrate. Bromine served as a protecting group. The debromination was later combined with another reduction process, thus not affecting the overall number of synthetic steps. Asymmetric crotylation of $\mathbf{5 2}$ on a 5 mmol scale furnished stereoselectively syn-homoallylic alcohol (-)-53 in 72\% yield and $94 \%$ ee. Synthesis of (-)-43 was accomplished in 9 steps from commercially available starting materials and in $10.5 \%$ overall yield. The compound and its analogs showed promising activity against clinical isolates of $M$. tuberculosis including multidrug resistant strain. 67

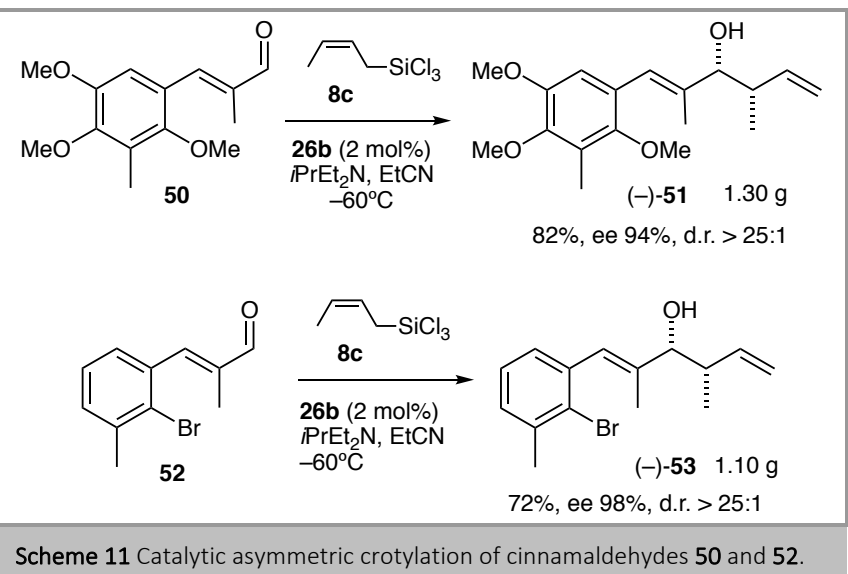

\section{Concluding Remarks}

Asymmetric crotylation of carbonyl compounds remains among the widely used synthetic tools enabling highly stereoselective construction of carbon framework. The former champions organoboron reagents bearing stoichiometric chiral auxiliaries are gradually giving way to highly enantioselective catalytic methods that employ achiral allylboronates and chiral catalysts to control enantiofacial selectivity. ${ }^{54,68-71}$ Methodology has been reported for the addition of chiral secondary allylboron reagents to aldehydes giving $E$-homoallylic alcohols in a highly stereoselective fashion; ${ }^{72}$ the substrate scope was further extended to ketones and imines. ${ }^{73}$ The elegant new catalytic methods for crotylation of aldehydes or alcohols that employ allylmetal species formed in situ from hydrocarbon precursors are increasingly gaining popularity in the synthetic community. ${ }^{4}$ 
However, among the plethora of new methods and reagents, allyltrichlorosilanes still hold their value. They are generally less expensive than the respective organoboron reagents and can be readily synthesized on a large scale in a single step from commercially available components. ${ }^{41}$ As Type I reagents, they offer high diastereoselectivity in crotylation, which combined with chiral Lewis base catalysts give rise to homoallylic alcohol in excellent enantio- and diastereocontrol. The method has now been also extended to propargylation of aldehydes. ${ }^{74,75}$ One of the issues still affecting versatility and competitiveness of the crotyltrichlorosilane reagents is low reactivity and enantioselectivity observed with aliphatic aldehydes. This has been partially addressed by the introduction of chinchona-based catalysts. ${ }^{43}$ However, the area continues to develop rapidly, and new solutions will undoubtfully emerge in the near future.

\section{Funding Information}

This work was supported by Russian Science Foundation Grant 18-73-10156

\section{Acknowledgment}

We would like to thank all our colleagues and collaborators who participated in the work described in this account. Their invaluable contribution is gratefully acknowledged.

\section{References}

1 S. E. Denmark and J. Fu, Chem. Rev., 2003, 103, 2763-2794.

2 J. W. J. Kennedy and D. G. Hall, Angew. Chem. Int. Ed., 2003, 42, 4732-4739.

3 M. Yus, J. C. González-Gómez and F. Foubelo, Chem. Rev., 2011 111, 7774-7854.

4 S. W. Kim, W. Zhang and M. J. Krische, Acc. Chem. Res., 2017, 50, 2371-2380.

5 J. M. Ketcham, I. Shin, T. P. Montgomery and M. J. Krische, Angew. Chem. Int. Ed., 2014, n/a-n/a.

6 E. L. McInturff, E. Yamaguchi and M. J. Krische, J. Am. Chem. Soc., 2012, 134, 20628-20631.

7 J. R. Zbieg, E. Yamaguchi, E. L. McInturff and M. J. Krische, Science, 2012, 336, 324-327.

8 I. S. Kim, S. B. Han and M. J. Krische, J. Am. Chem. Soc., 2009, 131, 2514-2520.

9 S. E. Denmark and E. J. Weber, Helvetica Chimica Acta, 1983, 66, 1655-1660.

10 H. C. Brown and K. S. Bhat, J. Am. Chem. Soc., 1986, 108, 293-294.

11 H. C. Brown and K. S. Bhat, J. Am. Chem. Soc., 1986, 108, 59195923.

12 W. R. Roush and R. L. Halterman, J. Am. Chem. Soc., 1986, 108 294-296.

13 W. R. Roush, K. Ando, D. B. Powers, A. D. Palkowitz and R. L. Halterman, J. Am. Chem. Soc., 1990, 112, 6339-6348.

14 B. M. Hackman, P. J. Lombardi and J. L. Leighton, Org. Lett., 2004 6, 4375-4377.

15 H. Kim, S. Ho and J. L. Leighton, J. Am. Chem. Soc., 2011, 133 6517-6520.

16 K. Iseki, Y. Kuroki, M. Takahashi, S. Kishimoto and Y. Kobayashi, Tetrahedron, 1997, 53, 3513-3526.

17 S. E. Denmark, D. M. Coe, N. E. Pratt and B. D. Griedel, J. Org. Chem., 1994, 59, 6161-6163.

18 S. E. Denmark and G. L. Beutner, Angew. Chem. Int. Ed., 2008, 47, 1560-1638.

19 P. Koukal, J. Ulč, D. Nečas and M. Kotora, Springer Berlin Heidelberg, Berlin, Heidelberg, 2017, vol. 40, pp. 3726-30.

20 Wrzeszcz and Siedlecka, Molecules, 2020, 25, 330-26.

21 A. V. Malkov, in Sustainable Catalysis, Royal Society of Chemistry, Cambridge, 2015, pp. 317-350

22 A. V. Malkov and P. Kočovský, Lewis Base-Catalyzed Reactions of SiX 3-Based Reagents with $C=0, C=N\left(n ? \rightarrow ? \sigma^{*}\right)$, John Wiley \& Sons Ltd, Weinheim, Germany, 2016, vol. I-III.

23 A. V. Malkov, M. Bella, V. Langer and P. Kočovský, Org. Lett., 2000, 2, 3047-3049
24 A. V. Malkov, D. Pernazza, M. Bell, M. Bella, A. Massa, F. Teplý, P. Meghani and P. Kočovský, J. Org. Chem., 2003, 68, 4727-4742.

25 M. Nakajima, M. Saito, M. Shiro and S.-I. Hashimoto, J. Am. Chem. Soc., 1998, 120, 6419-6420.

26 A. V. Malkov, M. Bell, M. Orsini, D. Pernazza, A. Massa, P. Herrmann, P. Meghani and P. Kočovský, J. Org. Chem., 2003, 68, 9659-9668.

27 A. V. Malkov, M. Orsini, D. Pernazza, K. W. Muir, V. Langer, P. Meghani and P. Kočovský, Org. Lett., 2002, 4, 1047-1049.

28 A. V. Malkov, M. Bell, M. Vassieu, V. Bugatti and P. Kocovsky, Journal of Molecular Catalysis A: Chemical, 2003, 196, 179-186.

29 A. V. Malkov, M. Bell, F. Castelluzzo and P. Kočovský, Org. Lett., 2005, 7, 3219-3222.

30 A. V. Malkov, S. Stoncius, M. Bell, F. Castelluzzo, P. Ramírez-López, L. Biedermannová, V. Langer, L. Rulísek and P. Kočovský, Chem. Eur. J., 2013, 19, 9167-9185.

31 A. V. Malkov, M. Barłóg, Y. Jewkes, J. Mikusek and P. Kočovský, J. Org. Chem., 2011, 76, 4800-4804.

32 A. V. Malkov, L. Dufková, L. Farrugia and P. Kočovský, Angew. Chem. Int. Ed., 2003, 42, 3674-3677.

33 A. V. Malkov, P. Ramírez-López, L. Biedermannová, L. Rulísek, L. Dufková, M. Kotora, F. Zhu and P. Kočovský, J. Am. Chem. Soc., 2008, 130, 5341-5348.

34 A. V. Malkov and P. Kočovský, EurJ Org Chem, 2007, 2007, 29-36.

35 T. Shimada, A. Kina, S. Ikeda and T. Hayashi, Org. Lett., 2002, 4, 2799-2801.

36 T. Shimada, A. Kina and T. Hayashi, J. Org. Chem., 2003, 68, 63296337.

37 A. Kadlčíková, R. Hrdina, I. Valterová and M. Kotora, Adv. Synth. Catal., 2009, 351, 1279-1283.

38 R. Hrdina, M. Dračínský, I. Valterová, J. Hodačová, I. Císařová and M. Kotora, Adv. Synth. Catal., 2008, 350, 1449-1456.

39 A. V. Malkov, M.-M. Westwater, A. Gutnov, P. Ramírez-López, F. Friscourt, A. Kadlčíková, J. Hodačová, Z. Rankovic, M. Kotora and P. Kočovský, Tetrahedron, 2008, 64, 11335-11348.

40 B. Bai, L. Shen, J. Ren and H.-J. Zhu, Adv. Synth. Catal., 2012, 354, 354-358.

41 P. S. O'Hora, C. A. Incerti-Pradillos, M. A. Kabeshov, S. A. Shipilovskikh, A. E. Rubtsov, M. R. J. Elsegood and A. V. Malkov, Chemistry, 2015, 21, 4551-4555.

42 Y. Fukazawa, V. Y. Vaganov, S. A. Shipilovskikh, A. E. Rubtsov and A. V. Malkov, Org. Lett., 2019, 21, 4798-4802.

43 Y. Huang, L. Yang, P. Shao and Y. Zhao, Chem. Sci., 2013, 4, 32753281.

44 S.-I. Sumida, M. Ohga, J. Mitani and J. Nokami, J. Am. Chem. Soc., 2000, 122, 1310-1313.

45 T.-P. Loh, K.-T. Tan and Q.-Y. Hu, Angew. Chem. Int. Ed., 2001, 40, 2921-2922.

46 A. V. Malkov, M. A. Kabeshov, M. Barłóg and P. Kočovský, Chemistry, 2009, 15, 1570-1573.

47 A. V. Malkov, O. Kysilka, M. Edgar, A. Kadlčíková, M. Kotora and P. Kočovský, Chem. Eur. J., 2011, 17, 7162-7166.

48 J. Nokami, K. Nomiyama, S. M. Shafi and K. Kataoka, Org. Lett., 2004, 6, 1261-1264.

49 C.-L. K. Lee, C.-H. A. Lee, K.-T. Tan and T.-P. Loh, Org. Lett., 2004 6, 1281-1283.

50 M. W. Andersen, B. Hildebrandt, G. Köster and R. W. Hoffmann, Chemische Berichte, 1989, 122, 1777-1782.

51 R. W. Hoffmann, Pure and Applied Chemistry, 1988, 60, 123-130.

52 R. W. Hoffmann and U. Weidmann, J. Orgamonet. Chem., 1980, 195, 137-146.

53 V. Rauniyar, H. Zhai and D. G. Hall, J. Am. Chem. Soc., 2008, 130, 8481-8490.

54 P. Jain and J. C. Antilla, J. Am. Chem. Soc., 2010, 132, 1188411886.

55 C. A. Incerti-Pradillos, M. A. Kabeshov and A. V. Malkov, Angew. Chem. Int. Ed., 2013, 52, 5338-5341.

56 L. Villar, N. V. Orlov, N. S. Kondratyev, U. Uria, J. L. Vicario and A. V. Malkov, Chem. Eur. J., 2018, 24, 16262-16265.

57 M. Sugiura, K. Hirano and S. Kobayashi, J. Am. Chem. Soc., 2004, 126, 7182-7183.

58 S. A. Look, W. Fenical, G. K. Matsumoto and J. Clardy, J. Org. Chem., 1986, 51, 5140-5145.

59 A. D. Rodríguez and C. Ramírez, J. Nat. Prod., 2001, 64, 100-102.

60 H. Correa, F. Aristizabal, C. Duque and R. Kerr, Marine Drugs, 2011, 9, 334-344.

61 R. R. Cesati III, J. de Armas and A. H. Hoveyda, J. Am. Chem. Soc., 2004, 126, 96-101.

62 H. M. L. Davies and A. M. Walji, Angew. Chem. Int. Ed., 2005, 44 1733-1735. 
63 J. S. Yadav, A. K. Basak and P. Srihari, Tetrahedron Letters, 2007 48, 2841-2843.

64 T. G. Elford, S. Nave, R. P. Sonawane and V. K. Aggarwal, J. Am. Chem. Soc., 2011, 133, 16798-16801.

65 J. S. Yadav, B. Thirupathaiah and A. Al Khazim Al Ghamdi, Eur J Org Chem, 2011, 2012, 2072-2076.

66 H. M. L. Davies and X. Dai, Tetrahedron, 2006, 62, 10477-10484.

67 A. Tkachenko, N. M. Kashevarova, R. Y. Sidorov, L. Y. Nesterova, A. V. Akhova, I. V. Tsyganov, V. Y. Vaganov, S. A. Shipilovskikh, A. E. Rubtsov and A. V. Malkov, Available at SSRN, 2020,

https://dx.doi.org/10.2139/ssrn.3696759.

68 H. Wang, P. Jain, J. C. Antilla and K. N. Houk, J. Org. Chem., 2013, 78, 1208-1215.

69 M. N. Grayson, S. C. Pellegrinet and J. M. Goodman, J. Am. Chem. Soc., 2012, 134, 2716-2722.
70 Y. Jiang and S. E. Schaus, Angew. Chem. Int. Ed., 2017, 56, 15441548.

71 D. S. Barnett, P. N. Moquist and S. E. Schaus, Angew. Chem. Int. Ed., 2009, 48, 8679-8682.

72 J. L. Y. Chen, H. K. Scott, M. J. Hesse, C. L. Willis and V. K. Aggarwal, J. Am. Chem. Soc., 2013, 135, 5316-5319.

73 J. L. Y. Chen and V. K. Aggarwal, Angew. Chem. Int. Ed., 2014, 53 10992-10996.

74 J. Chen, B. Captain and N. Takenaka, Org. Lett., 2011, 13, 16541657.

75 V. Y. Vaganov, Y. Fukazawa, N. S. Kondratyev, S. A. Shipilovskikh, S. E. Wheeler, A. E. Rubtsov and A. V. Malkov, Adv. Synth. Catal., 2020, 362, https://doi.org/10.1002/adsc.202000936.

\section{Biosketches}

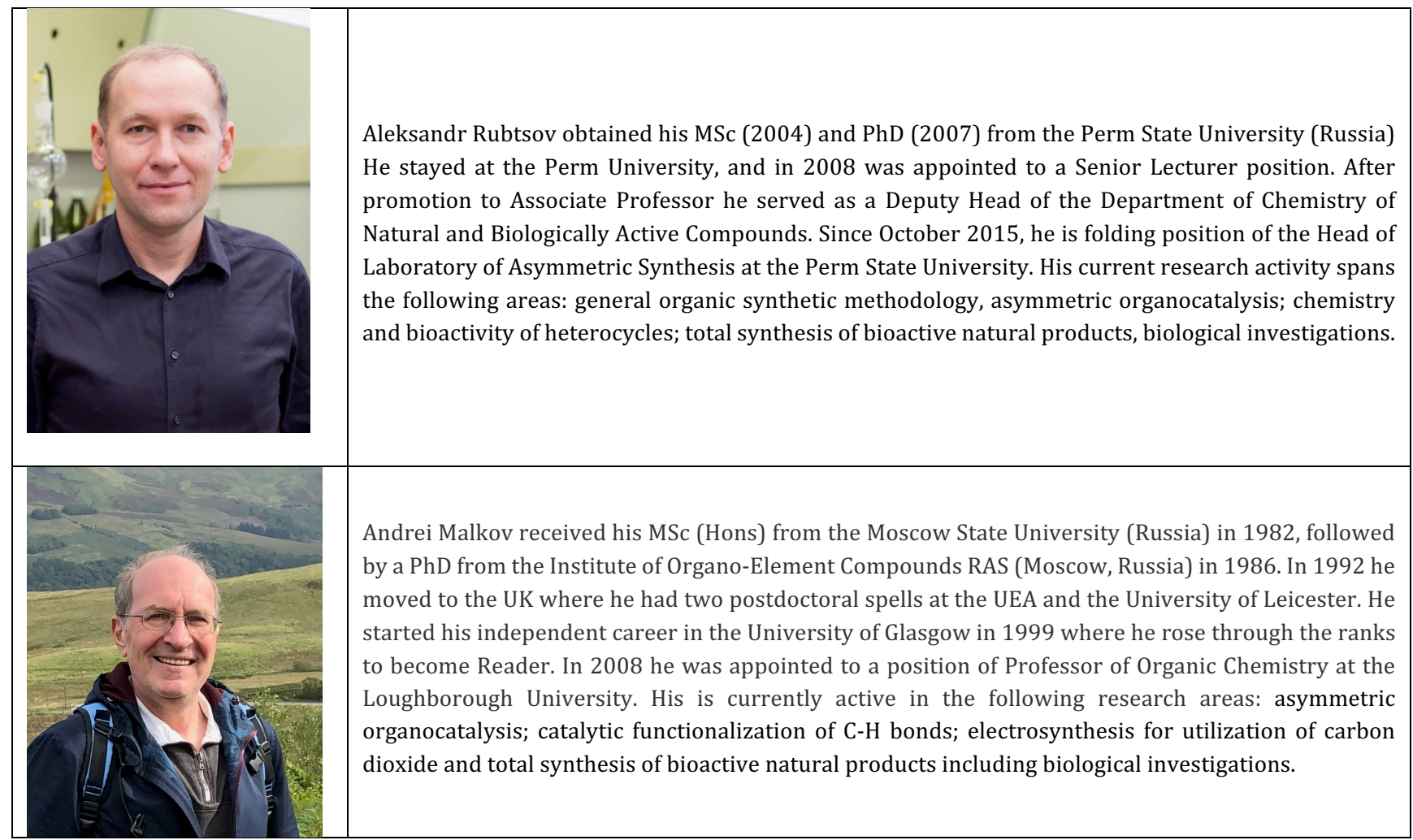

